\title{
Impact and Inclusion: Transforming an EdD Program into a Crucible for Systems Change
}

\author{
Antoinette M. Ryan \\ Central Connecticut State University \\ amryan@ccsu.edu \\ Sheldon Watson \\ Central Connecticut State University \\ watsonshl@ccsu.edu
}

\begin{abstract}
This article shares insights from a review of dissertations produced by students in an EdD program in Educational Leadership at a public university in Connecticut. Program curriculum and learning experiences, built upon a social justice platform, prepare students to engage in scholarship and action to improve educational systems. However, retaining students' focus on designing capstone projects that explore and seek to mitigate systemic injustice has been an ongoing challenge. To understand more about the impact of the EdD program's vision of developing students' capacities for systems transformation and social justice, program faculty conducted a document analysis of dissertations produced in the 15 years from program inception to the present, examining themes and trends that emerge from the focus areas, research questions, and research methods applied in dissertations. Document analysis revealed that, while earlier student dissertations tended to be more aligned with the educational policy cycle than with the program's focus on social justice, more recent dissertations demonstrate a shift toward a stronger social justice orientation. As a member of the Carnegie Project on the Educational Doctorate (CPED) since 2018, this university's EdD program engages in ongoing redesign to maximize impact on the field and to cultivate activism among program graduates who will lead systemic transformation in education. A conceptual framework for transcendent third-order change - cultivating systems leadership that transcends the limits of current paradigms and action, fosters collaborative engagement, and provides coherent structures for collaborative impact - is the foundation for this redesign.
\end{abstract}

\section{KEYWORDS}

social justice, EdD curriculum, systems transformation, third-order change leadership, collaborative engagement, collaborative impact

Central Connecticut State University (CCSU) is Connecticut's oldest publicly funded university. From its earliest years as a normal school, then as a teaching college, to its present as a comprehensive public university, CCSU has espoused a vision that values the creation of connections and partnerships with communities throughout the state. In addition to providing affordable access to degree programs, CCSU brands itself as a provider of intellectual resources, service, and support for helping communities address urgent or emergent economic, social, and cultural issues. The tiny state of Connecticut is a microcosm of the demographic and societal landscape of the U.S., with shared borders between suburban communities that possess great wealth and urban and rural communities besieged by systemic injustices. The greatest challenges of our society - including racism, meritocracy, socioeconomic/opportunity disparities, intolerance, and prejudices of all kinds - exist in each of Connecticut's 169 cities and towns, alongside the potential and capacity within those communities to create change in pursuit of a more just and thriving society. CCSU, situated in the heart of Connecticut, in an urban center both teeming with cultural wealth and struggling against economic challenges, has in many ways recognized and accepted its role as a hub, to nurture its increasingly diverse student population and by extension their communities.

It is against this backdrop that CCSU's graduate programming in Education Leadership emerged several decades ago with an enhanced vision for creating leaders to promote social justice in schools and districts. In particular, the more recently developed EdD program in Educational Leadership was built upon a social justice platform, with curriculum and learning experiences designed to illuminate the pressing urgencies of educational systems that do not serve, but rather oppress, students and communities. However, in the compliance- and standards-driven accountability era that has influenced practitioners and school districts since the inception of the EdD program, retaining students' focus on research and projects designed to examine social justice issues and to explore ways to mitigate injustice has been an ongoing challenge.

The EdD in Educational Leadership program at Central Connecticut State University (CCSU) has been serving cohorts of PK-12 doctoral candidates since 2002. Higher Education
New articles in this journal are licensed under a Creative Commons Attribution 4.0 United States License. 
Administration (HEA) candidates have now been included since 2016 in separate cohorts. Over 150 educators now hold the doctorate of practice degree from CCSU, and the first HEA graduates will don their regalia during the 2019-2020 academic year. Graduates have pursued the degree as a stepping stone to becoming school administrators at all levels, including superintendents, teacher leaders, and university faculty members. As a member of the Carnegie Project on the Educational Doctorate (CPED) since 2018, CCSU has launched an ongoing redesign of its program to maximize impact on the field. A primary goal of this redesign is to cultivate greater activism among program graduates to lead systemic change within education. The initial motivation for bringing an activist orientation to this program was grounded primarily in an intentional orientation toward social justice and promoting equity for marginalized groups. This orientation still exists as a driver of content in the program, and curriculum continues to be evaluated in regard to these outcomes. However, over the last several years, the activist agenda of the program has turned toward broad-based systems change, grounded in an expanded lens of what educational leadership needs to be in today's world. Current crises (e.g. climate change, growing social inequality, threats to democracy, a global epidemic of loneliness and depression, etc.), and the inability of traditional educational systems to display an agile response, demand bold new approaches.

\section{INTRODUCTION}

From its inception, the EdD program at CCSU has been focused on developing transformational school leaders (Burns, 1978; Leithwood \& Jantzi, 2000). Exactly what defines a transformational leader has been debatable. One of the most common monikers applied to a transformational leader, however, is that of change agent. Transformational leadership is generally regarded as the capacity to facilitate change in organizational behavior and culture; within educational settings, such change is oriented toward achieving goals that improve outcomes for students. This is casually thought of as challenging the status quo and inspiring new ways of seeing and being among organizational members. Within the context of the discipline of educational leadership, transformational leadership has also been often associated with leadership informed by social justice objectives (e.g. Larson \& Murtadha, 2002). Within the CCSU EdD program, transformative adult learning theory (Mezirow, 1991) has been a focal design principle to achieve this objective. Students are presented with learning experiences that challenge existing preconceptions and require the reintegration of their knowledge of practice with insights from scholarship. The cohort-based model provides a supportive chrysalis for these transformations, as the challenges become shared experiences.

Results have been mixed. From a values-based perspective, in which the need for deep change is a moral and ethical imperative (Scharmer \& Kaufner, 2013), the program has not achieved results significant enough to shift the educational status quo in local districts and schools in a manner that significantly challenges the surrounding systemic context of education. Change is often incremental and at the level of improvement of current processes, rather than deep shifts in vision, intention, or systems. This form of change has continued ultimately to serve the system as it is, if not in fact intensifying the system through the intensive enabling of top-down accountability regimes. As a review of the research topics that students have pursued in their dissertations demonstrates, relatively few EdD candidates have investigated topics or problems of practice related to social justice, equity, or structural oppression in their own schools or districts, or at the level of state policies that perpetuate injustice. Often, dissertation topics have aligned more with the demands of the neoliberal policy cycle that has controlled the attention, concern, and vision of educational leaders for nearly 40 years (Tyack \& Cuban, 1997). Still, program graduates have become successful leaders, who have brought some elements of transformational leadership to their practice. CCSU's EdD program leadership and faculty have re-oriented the vision and intention of the program to be more explicit about its commitment to a new, and deeper, level of fundamental change that has the potential to address the burgeoning needs that are present: namely, a transcendent third order of change (Bartunek \& Moch, 1987) as opposed to the conventional first and second orders of change often discussed in the best practice literature within the discipline of educational leadership. If graduates of the EdD program are to engage in the generative work of social justice, with the clear intention to create change in education so as to change society, transformational second order of change (Watzlawick, et al., 1974/2001) will not be a sufficient end goal. Second order change fails to address the core foundations and underlying assumptions of the existing system of public education. Systems change that occurs is confined to nodes within the system (e.g. implementing a new program within a school or district).

The analysis that follows, based upon a review of the dissertations completed from 2005 through 2019, confirms this point. Third-order change, with its focus on shifting entrenched social systems through ongoing critique of paradigms and structures, provides an important new concept for encouraging new directions for students pursing a dissertation-in-practice, which is a more intentional application of research to a problem of practice (Shulman, et al, 2006; Storey \& Maughan, 2016). Through preparation for pursuit of third-order change in curricular and research experiences, $\mathrm{EdD}$ candidates may engage in a capstone experience that is not only transformational, but transcendent in its intention and outcomes, situating their research into problems of practice as collaborative engagements within the communities most affected by systemic injustices, toward the creation of solutions.

\section{SCOPE AND PURPOSE}

This article shares findings that are part of an emergent process of developmental evaluation (Patton, 2011) of CCSU's EdD program, initiated by a review of dissertation topics in comparison to defined program learning outcomes. Developmental evaluation offers a bridge of support and monitoring of ongoing evolution and changes in complex, dynamic systems (such as education), provoked by the impetus toward innovation. From a systemic perspective, developmental evaluation monitors and evaluates innovation in context, providing data and information to change agents who seek to adapt systems and respond to impacts and events that occur in real time (Patton, 2011). From the time of the first CCSU EdD cohort's establishment to the present, the curriculum and learning experiences constructed by the EdD program leadership have largely been influenced by both the vision and mission of the program itself as one that fosters the development of leaders who understand and can create more socially-just systems, and by the need to respond to changing educational landscapes. Ongoing developmental evaluation in our EdD program has invited a form of 
double-loop learning (Argyris \& Schon, 1978) in action, with a parallel process in which we seek to understand the underlying norms and beliefs systems both within the program itself as well as in the contexts in which our students operate, as a means toward advancing the program's commitment to preparing leaders who can create more socially-just educational practices, environments, and systems amid the increasingly urgent need for change in the complex realities of educational systems and society.

The review of dissertations that were produced during the last 15 years by students in the EdD program in Educational Leadership at CCSU included collection of data on: topical foci; research questions; and, conceptual/theoretical frameworks. The conclusion, that program outcomes provide evidence of transformational leadership, but often in service of the status quo, offers a baseline for the subsequent and ongoing development in the evolution of the program toward transcendent, activist leadership outcomes. Key concepts that inform this approach are systems leadership (Senge, et al., 2015), collaborative engagement (Longo \& Gibson, 2016), and collective impact (Kania \& Kramer, 2011) and, ultimately, third order change (Bartunek \& Moch, 1987). This framework is discussed following the analysis of dissertations. Using these concepts as a foundation, the CCSU EdD program faculty are engaged in a recursive process of exploring the application of the CCSU EdD program principles in context. In beginning the process of developmental evaluation (Patton, 2011) we seek to examine the adaptive capacity of the EdD program, collecting data on student capstones and innovation in systems, and incorporating and respecting the context of stakeholders in a holistic evaluation of the program and student products. The authors share a framework for program design and outcomes as it continues to emerge from their own self-study.

\section{BACKGROUND}

The first guiding principle for EdD program design articulated by the CPED organization is that "The professional doctorate in education is framed around questions of equity, ethics, and social justice to bring about solutions to complex problems of practice" (CPED, n.d.). The problem with implementing this principle is that transformational leadership tends to produce responses to complex problems of practice, as opposed to solutions. This is because the underlying system that created such problems in the first place tends to remain unchanged. Yet transformational leadership is often the best outcome one can hope for from a preparation program unless it is explicitly framed around systems change. Genuine solutions to complex problems require a fundamental paradigm shift and accompanying change to systems themselves. As Tyack and Cuban (1997) have argued, the cycle of perpetual change associated with the history of school reform in the United States has contributed to very little actual substantive change to the underlying foundations of the system.

Contemporary school improvement discussions frequently call for second order change as a goal of educational leadership and reform. Two orders, or levels, of change lie at the center of this conceptualization (Watzlawick et. al, 1974). First order change is associated with the introduction of known solutions to known problems, with such solutions requiring fairly minimal changes in behavior on the part of participants. Second order change, alternatively, involves more fundamental change to an activity, process, or behavior of participants. Typically, second order change involves the introduction of new perspectives or paradigms. Findings of our developmental evaluation, however, suggest that new ways of doing things are overwhelmingly implemented within the existing structures of the system-as-it-is. The dissertations, topics, and conceptual frameworks we reviewed produced research that was primarily consistent with dominant narratives of prevailing policy cycles and mainstream best practice. Thus, the degree of change such "reforms" can achieve is limited and often unsustainable. What we see, in effect, are islands of transformation surrounded by an ocean of status quo realities associated with an underlying system that is highly resistant to change.

\section{METHOD}

To support the ongoing development of our EdD program toward advancing its vision of developing educational leaders who are willing and able to engage in transformation of systems for greater equity and justice, we conducted a review of CCSU EdD dissertations produced by students from the EdD program's inception in 2005 through the most recent available in 2019. Specifically, the review of dissertations sought to explore the ways in which notions of transformational leadership and social justice, espoused in the EdD program vision, influenced the focus areas, research questions, and research methods applied in dissertations. All 120 dissertations present in the CCSU EdD dissertation archives were reviewed, and the researchers collected data from the studies' introductory chapters and methods, applying a grounded theory approach to determine codes and categories among the sections reviewed.

In the initial review of program dissertations, analysis of the introductions and research questions revealed categories around which these dissertations' research centered, in the following areas:

- Student achievement and/or school improvement (primarily identified through outcomes on standardized assessments and other measures, such as graduation rates)

- Teacher practice, including: preparation, induction, professional development, instructional strategies, and content or instructional proficiency

- Leadership, including: instructional leadership; leadership attributes; approaches to leadership or leadership style

- Capacity and culture, including: collective- and selfefficacy

- $\quad$ Diversity, equity and social justice issues

A review of research methods employed in the studies indicated a substantial preference among students for mixed methods case study designs, with 76 approaching their research design using surveys, test data (primarily standardized tests, when exploring achievement) and interviews. Nearly a quarter of students (27 of 120) used exclusively quantitative methods, while the remaining 17 studies used exclusively qualitative methods. It is worth noting that, among the studies that focused on student achievement, school improvement, and/or assessments of the effectiveness of programs designed for specialized student supports, student researchers used primarily quantitative approaches in data collection and analysis. 


\section{FINDINGS}

In the data collected from 120 submitted dissertations, from the inaugural EdD cohort that published in 2005 to early 2019, several trends emerged among the research topics the program's doctoral students explored. First, dissertation foci reveal three distinct, chronologically-segmented "eras" among program cohorts that emerged: 2005-2009; 2010-2014; and 2015-present. Additionally, two "pivot" years (specifically, 2010 and 2015) demonstrated shifts in topics or focus areas that typified or anticipated the trends of the next era.

For example, during the first five years (2005-2009) of CCSU's EdD program's existence, at a time when the requirements of the No Child Left Behind Act ([NCLB], 2003) had become solidified in schools, EdD students demonstrated significant interest in student achievement and school-based reform (with 18 of 47 dissertations focused on student achievement as defined by standardized test outcomes), as well as studies of teacher practice and teacher induction (20 of 47 dissertations), while only one dissertation directly addressed diversity or social justice issues. During the second era (2010-2014), there was an emergence of interest in issues related to supporting diversity and social justice (four of 50 dissertations). In 2010-14, as policy requirements for test-based accountability, standardization, and educator evaluation affected virtually every aspect of teaching and administration in schools, a significant number of dissertations (13 of 50) focused on issues related to developing or assessing capacity among school staff or students and culture (including self- and collective efficacy). In addition, there was an increase in the orientation of dissertation foci that turned the lens on students' experiences and student empowerment. For example, rather than studying the effects of literacy or math programming on student achievement (which were the research foci of many dissertations in 2005-2009), studies in this second era focused on such topics as student empowerment in democratic schools, the needs of underperforming white males, and student employment and extra-curricular activity participation. Unlike earlier student achievement studies in 2005-2009, which focused on instructional practices and interventions and used metrics such as standardized tests, the more recent dissertation, particularly those completed in 2013-14, often situated students' experiences (e.g., with homework, self-efficacy, and racial isolation), at the center of the research focus. Finally, from 2015 to the present, dissertation research demonstrated a shift toward a stronger social justice orientation. Seven of 31 dissertations examined issues related to race, multicultural education, and gender identification. Dissertations focused on teachers examined the preparation of new teachers in high-poverty schools, experiences of Black male teachers, the role of race and culture in teachers' lives, and teaching for intercultural competence. Dissertations focused on leadership explored such topics as the processes of school and community partnerships, the experiences of Black female administrators in predominantly white districts, and perceptions of self and professional learning needs among leaders of "failing" schools and districts. During this era, topics such as ecojustice and sustainability, social media, and experiences of transgender and gender non-conforming youth appeared for the first time in program history.

\section{DISCUSSION}

The review of EdD program dissertations at CCSU reveals that trends in the educational policy cycle have coincided with the choice of students' dissertation topics/research foci, intentions, and methodologies. The analysis of the data also provides some important reflections for the transformation of the EdD program, including the evolution of the purpose, preparation for, and structure of the dissertation, setting the stage for the process of creating social innovation through dissertation research. Additionally, the review creates a platform for further inquiry into the transformational effects of dissertation projects in practice, on schools/districts where they took place and on practitioners conducting them.

A crucial aspect of transforming the program and evaluating its progress involves collaborative engagement with community stakeholders to address persistent challenges and measure impact within the changing contexts in which we do our work. The developmental evaluation process that this dissertation analysis initiates illuminates the distance between our program principles and enactment of them in student work, as we continue to learn from and with our students and community partners. From this analysis, the development of a conceptual framework for cultivating transcendent leadership emerges, through program coherence and creation of structures and intentional next-steps for supporting the EdD program goal of building the capacity of graduates to engage educational systems in transcendent third-order change.

\section{A SYSTEM CHANGE FRAMEWORK}

The current crises facing education, as well as the modern world, require full-scale systems change (Scharmer \& Kaufner, 2013). We suggest that even the oft-espoused holy grail of second order change, as promoted within the school improvement canon (e.g. Marzano, et al., 2005), is insufficient to achieve such change. In fact, such change may amplify the very same factors that are hastening system decline in education; essentially, they may reinforce the status quo. Third order change (Bartunek \& Moch, 1987), an overlooked conceptualization of change that supports the co-creation of new organizational realities, is what is required to achieve systems change at the level that is necessary. Third order change requires leadership that supports an organization in transcending the limits of current paradigms of viewing options for action; namely, third order change is transconceptual in nature and involves authentic escape from the status quo. According to Bartunek and Moch, the transconceptual element of third order change involves empowering members of organizations to grasp not only the operative organizational paradigm that is at work in their environment, but to then go one step further and understand that there are multiple alternative paradigms that can be brought to bear at any time. This discernment of multiple realities allows for multiframe thinking and more agile approaches to problem finding and solving. However, labeling the type of change we need is not the hard part. Actually, achieving third order change is the challenge of our time in many sectors. Facilitating such change requires a powerful toolkit for action and for grasping the dimensions of what one is acting upon. What is required is a whole new level of organizational learning.

Recent strategies and concepts associated with systems leadership (Senge et al., 2015), collaborative engagement (Longo \& Gibson, 2016), and collective impact (Kania \& Kramer, 2011) provide 
a promising roadmap to building capacity for third order change through multi-stakeholder organizational learning. First, systems leadership involves developing capacity to see the larger system for what it is, facilitating reflective and generative conversation among stakeholders, and moving the focus of stakeholders from reactive to proactive actions (Senge et al., 2015). Being able to discern the larger system at work, and the relationship between parts and the whole, allows stakeholders to identify leverage points for intervening with the system (Meadows, 2008; Stroh, 2015). For EdD candidates developing skills in organizational systems diagnosis (Heifetz, et al., 2009) may help in shifting their improvement focus from optimizing the system through business as usual reforms (Hassan, 2014), toward more substantive innovation. The concept of leverage points offers a way to pinpoint specific areas for significant impact and experimentation, as opposed to the daunting task of conceptualizing full-scale systems change (Stroh, 2015). Knowledge of the larger system at work creates possibility that even minor changes can lead to outcomes with broad ripple effects.

Next, the collective impact model (Kania \& Kramer, 2011) suggests that five conditions must be met to achieve success in systems change via the collective action of diverse stakeholders: 1 ) a common agenda is developed; 2) shared measurement systems are identified; 3) mutually reinforcing activities are developed; 4) continuous communication is present; and 5) underlying support structures are developed to support taking change to scale and achieving sustainability. Education is rife with reforms that come and go with limited time spans, with the underlying system regressing back to its previous state when pressure or resources are lifted (Tyack \& Cuban, 1997). The collective impact model is a framework of process and structure for taking the insights of adaptive systems leadership focused on leverage points and building a sustainable organizational infrastructure around it. It also offers opportunities to build in aspects of accountability, assessment, alignment and coherence (Kania \& Kramer, 2011); all desirable qualities of the existing systems we already operate within. Thus, the collective impact model may provide a bridge between the status quo and what comes next. Systems leadership efforts must promote interdependence to be effective (Hassan, 2014). The intrinsic value of engagement with diverse stakeholders, and how to go about doing it, must be an embedded component of an EdD program with learning outcomes centered on advocacy and activism.

Collaborative engagement (Longo \& Gibson, 2016) is a model from the literature on community engagement in higher education that we apply to change leadership activity in PK-12 organizational systems. The essential argument of this model is that deep systems change requires proactive, ongoing engagement with diverse stakeholders to identify new pathways to achieving common goals and shared ownership of social knowledge (Martin \& Crossland, 2017). Adaptation and innovation, accomplished through collection action, is the objective of this approach. Systems tend to be highly resilient to change due to the presence of balancing and reinforcing feedback loops of both factors and actors in the system (Stroh, 2015). Bringing together diverse stakeholders serves as a mechanism to more easily identify such feedback loops and correct or disrupt them as necessary. Through this lens, the change agent becomes only as influential as the change coalition they can assemble. For doctoral students, the shared experience of the cohort model helps bring this concept to life, as the individual agency of each student is powerfully influenced by the conjoint agency of the group. The next step is to translate that vision of interdependence to the field and to the work of assembling diverse stakeholders to tackle complex problems impacting youth and education.

In the CCSU EdD program, this framework influences much of the learning experience in educational leadership. Among the critical perspectives we apply is that, in moving from transformational to transcendent leadership, we are aware of the potential of EdD programming and curriculum to either unwittingly exacerbate inequitable, harmful systems, or to intentionally, and from an awareness-based perspective, transcend traditional modes of creation, and with community partners, co-creation, of approaches in educational leadership that spark innovation. Developmental evaluation processes assist us in this effort. Cohort coursework and field-based activities are focused on developing systems thinking and mapping skills. Doctoral candidates critique their own role in maintaining and reproducing a system that does not produce the overall results anyone wants. Students engage with external stakeholders to gather unique perspectives and to hear marginalized voices. They learn strategies and concepts from improvement science (Bryk, et al., 2015) in order to identify leverage points for intervening in the system through rapid prototyping of innovative practices. Perhaps most importantly, they learn about themselves and about truly engaging with others to do the work of change. These leadership skills recognize that third order change starts on the inside, but that when it radiates out to encompass more and more individuals it can lead to turning a system into something fundamentally different than it was before.

Program faculty are not left out of this process. A team of faculty have recently formed their own innovative work team and joined a cohort of 300 teams from around the world to participate in u.lab.2x, a multi-local collaborative learning journey facilitated by systems change experts from the Presencing Institute and grounded in the Theory $U$ (Scharmer, 2018) model of individual and group learning. Through this work, the CCSU EdD faculty are modeling Theory $U$ and $u$.lab. $2 x$ strategies in classroom practice and are developing their own model of multi-stakeholder engagement "hubs." Hub members - which include educators from a variety of organizations, students, community service providers and organizers - collaborate to generate new approaches for addressing persistent, seemingly intractable, issues (e.g. systemic marginalization of students of color) that can then be applied in the local field of public education, in the form of innovative, systems-based solutions to catalyze change. Developmental evaluation processes offer hub strategists opportunities to use data from implementations in real time, to facilitate insights regarding the efficacy of such innovations, and to adapt responses to shifting dynamics. In doing so, and in enacting their own activism in the field, faculty will then be even more prepared to help cultivate such skills in the next wave of educational leaders. The time has come for everyone to become an activist. Education can adapt, transcend its current limitations, and play a key role in building capacity to support such action.

\section{REFERENCES}

Argyris, C., \& Schon, D. (1978). Organizational learning: A theory of action perspective. Addison-Wesley.

Bartunek, J. M., \& Moch, M. K. (1987). First-Order, Second-Order, and ThirdOrder Change and organization development interventions: A cognitive approach. The Journal of Applied Behavioral Science, 23(4), 483-500. https://doi.org/10.1177/002188638702300404 
Bryk, A. S., Gomez, L. M., Grunow, A., \& LeMahieu, P. G. (2015). Learning to improve: How America's schools can get better at getting better. Harvard Education Press.

Burns, J. M. (1978). Leadership. Harper and Row.

Hassan, Z. (2014). The social labs revolution: A new approach to solving our most complex challenges. Berrett-Koehler Publishers, Inc.

Heifetz, R., Grashow, A., \& Linsky, M. (2009). The practice of adaptive leadership: Tools and tactics for changing your organization and the world. Harvard Business Press.

Kania, J., \& Kramer, M. (2011, Winter). Collective impact. Stanford Social Innovation Review. https://ssir.org/articles/entry/collective_impact.

Larson, C., \& Murtadha, K. (2002). Leadership for social justice. In J. Murphy (Ed.), The educational leadership challenge: Redefining leadership for the 21 st century. University of Chicago Press.

Leithwood, K. and Jantzi, D. (2000). The effects of transformational leadership on organizational conditions and student engagement with school. Journal of Educational Administration, 38(2), 112129. https://doi.org/10.1108/09578230010320064

Longo, N. V., \& Gibson, C. M. (2016). Collaborative engagement: The future of teaching and learning in higher education. In M. A. Post, E. Ward, N. V. Longo, and J. Saltmarsh (Eds.), Publicly engaged scholars: Next generation engagement and the future of higher education (pp. 61-75). Stylus Publishing.

Martin, L., \& Crossland, S. (2017). Competencies community engagement professionals need for faculty development. In L.D. Dostillo (Ed.), The community engagement professional in higher education: A competency model for an emerging field (pp.161-178). Campus Compact.

Marzano, R., Waters, T, McNulty, B.A. (2005). School leadership that works: From research to results. Association for Supervision and Curriculum Development (ASCD).

Meadows, D. H. (2008). Thinking in systems: A primer. Chelsea Green Publishing.

Mezirow, J. (1991). Transformative dimensions of adult learning. Jossey-Bass.

No Child Left Behind (NCLB) Act of 2001, 20 U.S.C.A. $§ 6301$ et seq. (West 2003)

Patton, M.Q. (2011). Developmental evaluation: Applying complexity concepts to enhance innovation and use. Guilford Press.

Scharmer, O. (2018). The essentials of Theory U: Core principles and applications. Berrett-Koehler Publishers, Inc.

Scharmer, O., \& Kaufner, K. (2013). Leading from the emerging future: From ego-system to eco-system economies. Berrett-Koehler Publishers.

Shulman, L. S., Golde, C. M., Bueschel, A. C., \& Garabedian, K. J. (2006). Reclaiming education's doctorate: A critique and a proposal. Educational Researcher, 35(2), 25-32.

Senge, P., Hamilton, H., \& Kania, J. (2015, Winter). The dawn of system leadership. Stanford Social Innovation Review. https://ssir.org/articles/entry/the_dawn_of_system_leadership

Storey V.A., \& Maughan B.D. (2016) Dissertation in practice: Reconceptualizing the nature and role of the practitioner-scholar. In V.A Storey (Ed.), International Perspectives on Designing Professional Practice Doctorates. Palgrave Macmillan.

Stroh, D.P. (2015). Systems thinking for social change: A practical guide to solving complex problems, avoiding unintended consequences, and achieving lasting results. Chelsea Green Publishing.

Tyack, D., \& Cuban, L. (1997). Tinkering toward utopia. Jossey-Bass.

Watzlawick, P., Weakland, J. H., \& Fisch, R. (1974/2011). Change: Problem formation and problem resolution. W. W. Norton \& Co. 